\title{
APPLICATION OF A DECISION SUPPORT SYSTEM BASED ON THE ANALYTIC NETWORK PROCESS TO IMPROVE STATE PROGRAM OF MEDICINES SOCIAL ASSISTANCE
}

\author{
Onischenko Daria Ivanovna \\ Belgorod State Technological University \\ Belgorod, Russia \\ E-mail: d.i.onischenko@yandex.ru \\ Sinuk Vasilij Grigorjevich \\ Belgorod State Technological University \\ Belgorod, Russia \\ E-mail:vgsinuk@mail.ru
}

\begin{abstract}
Nowadays deficiency economic and social decisions increased the price that society has to pay. The increasing requirements for management quality in various spheres of human activity make it necessary do a special analytical work in decision-making. A manager shouldn't make a decision intuitively, and he should use the appropriate tools to find the best options and justify the choices made. This article deals with such social problem as choosing the best state program of medicines social assistance for benefit recipients using Super Decisions tools, supporting network analysis method. Structure of the problem solution has been developed. The phase of discrimination and comparative judgments, and the phase, associated with the synthesis have been described. Recommendations based on the results received have been made.
\end{abstract}

Keywords: state program, medicines social assistance, social decisions, analytic network process, bocr model, benefits, risks, synthesis.

\section{Introduction}

The problem of social assistance still remains one of the most important and complex problems. Despite the amendments to the Russian Federal Law "On State Social Assistance", a lot of benefit recipients remain unsatisfied with the modern social program. The study of modern requirements of benefit recipients, using social packages arrived at the conclusion to improve the social assistance system. Among the services offered by social packages, the most important problem was providing benefit recipients with free essential medicines. Every day a number of federal benefit recipients increases. One day each of us may face the necessity of social assistance, so the problem deserves attention from the state.

\section{Literature Review}

As a result, the detailed study of the problem provision of benefit recipients, using social packages with medicines revealed the following: 
D.I.Onischenko, V.G.Sinuk/Application of a decision support system based on the ANP to improve state program of medicines social assistance.

1. The number of state pharmacies, providing medicines within the social package is very small.

2. The amount of medicines in state pharmacies is very limited.

3 . Some medicines come with great delays, which makes the timely receiving of vital medicines (eg, insulin) impossible.

4. In case the medicine prescribed are absent in the state pharmacies cheaper and sometimes less effective medicines are offered.

5. Besides benefit recipients can reject from providing medicines in favor of money, the amount of which does not cover possible future medicines costs.

The main objective of the study is to evaluate possible alternatives to improve the state program of medicines social assistance for benefit recipients within the social package in Russia.

\section{Hypotheses/Objectives}

\subsection{The purpose of the study}

To choose the best solution for improving state program of medicines social assistance.

\subsection{Alternatives}

1. Expanding the network of state pharmacies.

The increase of the number of state pharmacies due to the budget funds. This alternative would avoid delays in providing medicines as well as improve the possibility to buy prescription medicines. Besides this alternative can bring profit to the state at the expense of sales of non-prescription medicines.

2. Increasing the number of medicines outlets due to private pharmacies.

This alternative envisages attracting owners of private pharmacies to the program of medicines social assistance by the state. This alternative would reduce the costs for expanding the network of pharmacies, the erection of new buildings and providing jobs.

3. Increase of fixed compensation payments to benefit recipients.

Currently fixed cash payments for medicine coverage amount up to 646.71 rubles. This alternative proposes to increase the amount of cash payments.

4. Provision and calculation of individual cash payments to benefit recipients.

This alternative provides individual cash payments instead of providing prescription medicine. Thus, it is possible to buy medicines at private pharmacies without waiting for medicines at the state pharmacies.

5. Rejection of the change of prescribed medicines for cheaper ones.

Another suggestion to improve the quality of social services. Currently the medicines prescribed by a doctor and absent in the state pharmacies can be substituted by other medicines. Sometimes substitution medicines are cheaper (which is beneficial for the state), but are less effective than the prescribed ones. This alternative offers to reject such substitutions.

All alternatives are assessed taking into account the Risks and Benefits.

\section{Research Design/Methodology}

The problem of decision making is a weakly structured one. The problem is complex and it is very difficult to show all aspects. Communication with the expert showed that the best solution of the problem can be found using the method of decision-making on the basis of analytical and process network. This method allows to build models based on the 
information obtained from an expert, taking the influence of qualitative factors into account as well as to test various hypotheses in the structure of the intensity of various factors. Data to fill the matrix of pairwise comparisons have been provided by an expert.

\section{Data/Model Analysis}

For each control criterion its own network is constructed. The model uses the management hierarchy, including 2 generalized criteria: Benefits and Risks (Figure 1). For each of the criteria the network model of interaction of the factors presented by the components which consisting of elements was constructed. Thus, two network model (Figure 2), each of which corresponds to one control criterion have been constructed.

\subsection{Actors}

1. State.

2. Owners of private pharmacies.

3. Federal benefit recipients.

\subsection{Risks}

Figure 1 General scheme of the problem.

1. Taxation increase. The taxpayers' money comes to the state budget, and then it is appropriated for running social program.

2. Lack of money in the state budget. Improvement of social program of medicines social assistance is cost-based.

3. Development of the shadow economy. Partial sale of medicines and high costs might increase the share of shadow business.

4. Financial losses. Money damages arising from unforeseen payments, payment of additional taxes, as well as inflation and exchange rate changes. In addition, financial losses can result from shortfall or non-receipt of money from the planned sources, decreasing revenue as a result of lowering prices for the products and services.

5. Increased morbidity. There is a risk of increasing the number of disabled and sick due to incorrectly conducted social programs.

\subsection{Benefits}

1. Constant availability of essential medicines in pharmacies.

Benefit recipients can receive lifesaving medications on time.

2. Increasing the number of medicine outlets.

Medicines are absent one pharmacy, then they can be obtained in the other.

3. Increasing the number of working-age population.

Many people with disabilities still work, despite the benefits. Improving their health could lead to a similar benefit.

4. Increasing demographic lines.

International Symposium of 
D.I.Onischenko, V.G.Sinuk/Application of a decision support system based on the ANP to improve state program of medicines social assistance.

Improving social program influences public health

5. Increasing the number of jobs.

In connection with the expansion of the network of pharmacies a lot of jobs become available what is beneficial both for the public and the state.

6. Decreasing of cash costs in the future.

The improvement of living standards of the population now can significantly reduce the state spending in the future.

\subsection{Strategic criteria}

1. Health of the Nation. Influence improvements of the health of people, life expectancy and efficiency due to the improvements of the state program of medicines social assistance.

2. Profit. The profit brought to the State by the best alternative.

3. Psychological factor. The response of people to the decisions made by the state.

a)
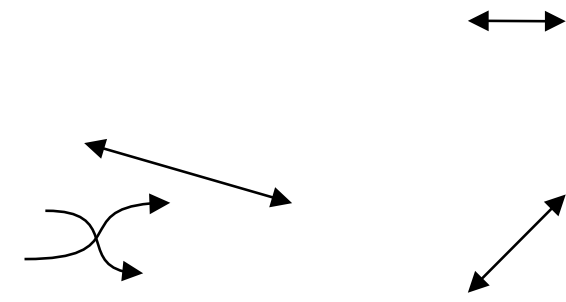

b)
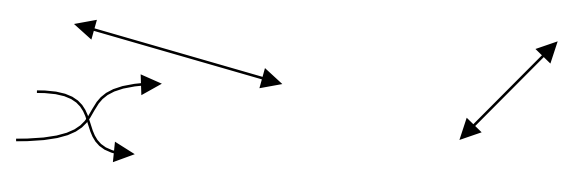

Figure 2 Network model of a) Benefits and b)Risks.

Taking into account the strategic criteria affecting the goal, as well as Benefits and Risks associated with the proposed alternatives one can get the best alternative with respect to the target.

The second step is to construct a matrix of pairwise comparisons first for the cluster, and then for the elements. When considering network models the Benefits and Risks supermatrices were built. In the diagram (Figure $3 \mathrm{a}, \mathrm{b}$ ) you can see how the alternatives have been prioritized by synthesis. 
D.I.Onischenko, V.G.Sinuk/Application of a decision support system based on the ANP to improve state program of medicines social assistance.

\begin{tabular}{|l|l||||||||||||}
\hline a) Subnet under Benefits: formulaic \\
\hline \multicolumn{1}{|c|}{ Name } \\
\hline $\begin{array}{l}\text { 1. Expanding the network } \\
\text { of state pharmacies }\end{array}$
\end{tabular}

\begin{tabular}{|l|l||l|||}
\hline \multicolumn{1}{|c|}{ b) Subnet under Risks: formulaic } \\
\hline \hline \multicolumn{1}{|c|}{ Name } \\
\hline $\begin{array}{l}\text { 1. Expanding the network } \\
\text { of state pharmacies }\end{array}$ \\
\hline \begin{tabular}{l}
\hline 2. Increasing the number of \\
medicines outlets due to $\sim$
\end{tabular} \\
\hline $\begin{array}{l}\text { 3. Increase of fixed } \\
\text { compensation payments } ~\end{array}$ \\
\hline $\begin{array}{l}\text { 4. Provision and calculation } \\
\text { of individual cash payments }\end{array}$ \\
\hline $\begin{array}{l}\text { 5. Rejection of the change } \\
\text { of prescribed medicines } ~\end{array}$
\end{tabular}

Figure 3 Distribution of the priorities of alternatives in the model of a) Benefits and b)

Risks

At the third step the synthesis of the priorities of alternatives on the network model is being made. These priorities of the alternatives obtained by analysis of Benefits and Risks, as well as the priorities of the strategic criteria are taken into account (Figure 4).

\begin{tabular}{|c|c|c|c|c|}
\hline & Priorities & 1. Health of the Nation & 2. Profit. & 3. Psychological factor. \\
\hline Benefits & 0.690327 & 1.0 & 1.0 & 0.281135 \\
\hline Risks & 0.309673 & 0.079042 & 0.281135 & 1.0 \\
\hline
\end{tabular}

Figure 4 Priorities of Benefits and Risks with respect to the strategic criteria.

Synthesis of the final priorities of alternatives depending on the strategic criteria is made by two methods. Because of the lack of Opportunities and Costs in this problem the synthesis is made according to by the following formulae:

- the additive (negative) formula: $\mathbf{b B}$ - rR

- the multiplicative formula: $\mathbf{B} / \mathbf{R}$

\begin{tabular}{|c|c|c|c|c|c|c|c|c|c|}
\hline a) $\quad$ Name & Graphic & Ideals & Normals & Raw & Name & Graphic & Ideals & Normals & Raw \\
\hline $\begin{array}{l}\text { 1. Expanding the network } \\
\text { of state pharmacies }\end{array}$ & & 1.000000 & 0.440021 & 0.581465 & $\begin{array}{l}\text { 1. Expanding the network } \\
\text { of state pharmacies }\end{array}$ & & 1.000000 & \begin{tabular}{|l|l|} 
& 0.495302 \\
\end{tabular} & 2.844640 \\
\hline $\begin{array}{l}\text { 2. Increasing the number of } \\
\text { medicines outlets due to } \sim\end{array}$ & & 0.611697 & 0.269160 & 0.355680 & $\begin{array}{l}\text { 2. Increasing the number of } \\
\text { medicines outlets due to } \sim\end{array}$ & & 0.338821 & 0.167819 & 0.963824 \\
\hline $\begin{array}{l}\text { 3. Increase of fixed } \\
\text { compensation payments }\end{array}$ & & 0.013449 & 0.005918 & 0.007820 & $\begin{array}{l}\text { 3. Increase of fixed } \\
\text { compensation payments }\end{array}$ & & 0.169175 & \begin{tabular}{|l|l|}
0.083793 \\
\end{tabular} & 0.481242 \\
\hline $\begin{array}{l}\text { 4. Provision and calculation } \\
\text { of individual cash payments }\end{array}$ & & 0.634557 & 0.279219 & 0.368973 & $\begin{array}{l}\text { 4. Provision and calculation } \\
\text { of individual cash payments }\end{array}$ & & 0.380377 & 0.188402 & 1.082037 \\
\hline $\begin{array}{l}\text { 5. Rejection of the change } \\
\text { of prescribed medicines }\end{array}$ & & -0.012915 & $\mid-0.005683$ & $\mid-0.007510$ & $\begin{array}{l}\text { 5. Rejection of the change } \\
\text { of prescribed medicines } \sim\end{array}$ & & 0.130596 & 0.064684 & 0.371498 \\
\hline
\end{tabular}

Figure 5 a) Additive result. b) Multiplicative result.

As a result of synthesis the results of the additive and multiplicative approach resulted in the same ranking of alternatives. Alternatives are in the following order:

- Expanding the network of state pharmacies - 49.53\%

- Provision and calculation of individual cash payments to benefit recipients $-18.84 \%$

- Increasing the number of medicines outlets due to private pharmacies - $16.78 \%$

- Increase of fixed compensation payments to benefit recipients - $8.37 \%$

- Rejection of the change of prescribed medicines for cheaper ones $-6.46 \%$

The best one is the first alternative.

\section{Limitations}

The number of alternatives proposed as a problem solution is rather limited. Due to the complex type problem, it can't be considered in a particular aspect. It's virtually impossible to take into account all the criteria and connections in the model. Perhaps 
D.I.Onischenko, V.G.Sinuk/Application of a decision support system based on the ANP to improve state program of medicines social assistance.

some of them were not taken into account in the created model. In this connection the result can be subjective and inaccurate. Perhaps this study should be expanded to increase the number of alternatives, criteria and actors, to attract more experts.

\section{Conclusions}

In the course of the research the problem of multi-criteria analysis was solved, the aim of which was to choose the best solution to improve state program of medicines social assistance. Expanding the network of state pharmacies was the best solution. Provision and calculation of individual cash payments to benefit recipients took the second place. The expert suggested that the solution was the first alternative, and his intuition did not fail. The worst alternative proved to be the rejection of the prescribed medicines for cheaper substitutes.

Since the problem to be solved in the project is actual, the results obtained in the course of its solution, may be useful for the distribution of budget funds.

The created model can be used in future for to solving such problems.

\section{Key References}

T.L.Saaty Decision-making at the dependencies and feedbacks: Analytical network. Translate from English. / Scientific ed. A.V. Andreychikov, O.N. Andreichikova: Russia, Publishing house: LKI, 2008. - $360 \mathrm{p}$.

T.L.Saaty Decision making. Methods of analysis of hierarchies, Translate from English. R. G. Wachnadze - Russia, Publishing house: Moscow "Radio and communication", 1993. -278 p.

T.L.Saaty, L.G.Vargas Decision making with the Analytic Network Process: Economic, Political, Social and Technological Applications with Benefits, Opportunities, Costs and Risks. 2006 by Springer Science+Business Media, LLC.

Federal benefits to beneficiaries.. URL:http://giperkan.ru/polezno-i-interesno/lgotifederalnim-lgotnikam.html

The list of benefits for people with disabilities 2013-2014 year. URL: http://doorinworld.ru/stati/504-perechen-lgot-na-2011-god

ORDER MZSF of 14 December 2005 N 785 ON THE ORDER OF DRUG RELEASE URL:http://www.unico94.ru/official/docs/show/?Id=1937\&main_id=1937 